\title{
Suplementação de enzimas exógenas em dieta microparticulada para larvicultura do pacu
}

\author{
Marcelo Borges Tesser ${ }^{1}$, Carolina Isabel Flores-Quintana ${ }^{2}$, Dalton José Carneiro ${ }^{3}$, João \\ Martins Pizauro Junior ${ }^{4}$, Maria Célia Portella ${ }^{3}$
}

\author{
1 UNESP - Centro de Aqüicultura - Discente do curso de Doutorado. \\ 2 UNNE - Faculdad de Veterinária - Argentina - Docente. \\ 3 UNESP - Centro de Aqüicultura - Docente. \\ 4 UNESP - Departamento de Tecnologia - Docente.
}

RESUMO - Este experimento foi realizado para avaliar os efeitos da suplementação de enzimas exógenas (pancreatina suína) em microdietas sobre o crescimento, a sobrevivência e as alterações morfológicas do trato digestório de larvas de pacu, Piaractus mesopotamicus. Foram testados oito programas alimentares: alimentação exclusiva com náuplios deArtemia (AV); alimentação exclusiva com dieta microparticulada com (DMP) ou sem (DM) suplementação enzimática; substituição, aos cinco dias, dos náuplios deArtemia por dietas inertes com (AV5DMP) ou sem (AV5DM) suplementação; e substituição dos náuplios aos dez dias por dietas com (AV10DMP) ou sem (AV10DM) suplementação. O experimento teve duração de 28 dias. Larvas que receberam o alimento vivo durante todo o período experimental apresentaram maiores médias de peso. O efeito negativo da supressão do alimento vivo sobre o crescimento das larvas foi verificado tanto na substituição aos cinco dias como aos dez dias. No entanto, nas avaliações biométricas subseqüentes, observaram-se efeitos positivos da suplementação enzimática; a partir do $20 \mathrm{Q}$ dia de experimento, as larvas que receberam a dieta suplementada com enzima exógena apresentaram peso médio estatisticamente superior ao daquelas alimentadas com a dieta sem suplementação. As diferenças morfológicas mais evidentes proporcionadas pela suplementação enzimática foram observadas nas larvas que receberam substituição alimentar aos cinco dias. As diferenças foram relativas à quantidade de grânulos de zimogênio no pâncreas e às inclusões supranucleares no intestino. As larvas submetidas à transição alimentar aos dez dias de experimento já apresentavam diferenciação morfológica do sistema digestório mais avançada, assemelhando-se muito às larvas do tratamento com alimento vivo. Os resultados deste experimento indicam que a suplementação com pancreatina proporcionou efeitos positivos sobre o crescimento e a sobrevivência das larvas de pacu.

Palavras-chave: alimentação de larvas, dieta inerte, pancreatina, suplementação enzimática, transição alimentar

\section{Exogenous enzyme supplementation on microdiet for pacu larviculture}

\begin{abstract}
This experiment aimed to determine the effects of exogenous enzyme (porcine pancreatin) supplementation to microdiet on pacu Piaractus mesopotamicus growth, survival and changes on digestive tract morphology. Eight feeding programs were performed: Artemia nauplii feeding (AV), microdiet with enzymatic supplementation (DMP) or without supplementation (DM), weaning at the $5^{\text {th }}$ day with supplemented (AV5DMP) or not supplemented diet (AV5DM) and weaning at the $10^{\text {th }}$ day with supplemented diet (AV10DMP) or not supplemented diet (AV10DM). The experiment lasted 28 days. Larvae fed only alive prey during the whole period showed the highest mean weight values. The negative effect of Artemia suppression on larvae growth was noted on those which were weaned either on the $5^{\text {th }}$ or $10^{\text {th }}$ day of experiment. However, at the next growth evaluation, positive effects of enzyme supplementation were observed. After the $20^{\text {th }}$ of experiment, the larvae fed exogenous enzyme supplemented diet showed higher mean weight values than larvae fed diet without supplementation. The most noticeable morphological changes between larvae that received the enzyme supplementation or not was observed for larvae weaned at the $5^{\text {th }}$ day of experiment. The differences were on the amount of zymogen granules in the pancreas and intestine supranuclear inclusion. On the other hand, larvae weaned at the $10^{\text {th }}$ of the experiment presented more advanced morphological differentiation, similarly to the larvae fed alive prey. The results of this experiment show positive effects of pancreatin supplementation on pacu larvae growth and survival.
\end{abstract}

Key Words: enzymatic supplementation, inert diet, larvae feeding, pancreatin, weaning 


\section{Introdução}

As larvas de peixes, ao eclodirem, possuem trato digestório mais simples que o de peixes adultos da mesma espécie (Govoni et al., 1986). No entanto, mesmo com esta suposta simplicidade, as larvas de peixes teleósteos possuem grande potencial de crescimento, 10 a $100 \%$ por dia (Conceição et al., 1998), o que geralmente não é observado quando passam precocemente pela transição do alimento vivo para o alimento inerte, resultando muitas vezes em baixo crescimento e elevada mortalidade (Tesser et al., 2005).

Vários fatores contribuem para o pequeno sucesso na alimentação de larvas de peixes com dietas inertes. As causas variam desde a falta de estímulo visual das dietas inertes as larvas ingerem principalmente organismos vivos durante os primeiros dias de desenvolvimento (Planas \& Cunha, 1999) - até a natureza intrínseca das partículas de alimento, como textura, sabor, cor, formulação e tamanho. Esses fatores afetam a aceitabilidade, a digestibilidade e a lixiviação de nutrientes (Önal \& Langdon, 2000).

Alguns autores atribuíram o insucesso da utilização de microdietas à baixa organização do trato digestório das larvas, o que resultaria em reduzida atividade enzimática (Dabrowski, 1984; Lauff \& Hoffer, 1984). Por outro lado, a maioria das enzimas pancreáticas é detectada desde a abertura da boca (Cousin et al., 1987; Boulhic \& Gabaudan, 1992). Kolkovski (2001) alegou que a atividade enzimática suficiente para digerir organismos vivos pelas larvas de peixes pode ser insuficiente para digerir uma microdieta seca. Além disso, algumas proteínas comumente utilizadas na formulação de microdietas possuem atividade inibitória de proteases digestivas (Alarcón et al., 1999), assim como fatores antinutricionais.

Kurokawa et al. (1998), estudando a contribuição de enzimas digestivas provenientes dos organismos vivos para larvas de sardinha (Sardinops melanotictus), observaram que a contribuição de proteases exógenas seria insignificante no processo digestivo larval, contribuindo com menos de $1 \%$ do total de proteases presentes na larva. No entanto, resultados positivos têm sido relatados na literatura apontando sucesso da utilização da alimentação conjunta de organismos vivos e dieta inerte, resultando em maior crescimento das larvas comparativamente àquelas larvas alimentadas somente com organismos vivos (Holt, 1993; Rosenlund et al., 1997). Entretanto, os resultados sobre os efeitos da suplementação enzimática sobre o crescimento larval (Kolkovski, 2001) ainda são controversos.

As alterações morfológicas no sistema digestório decorrentes da alimentação em larvas de peixes têm sido avaliadas no sentido de complementar as informações geradas em estudos zootécnicos (Rösch \& Segner, 1990). Bengston (1993) citou que o insucesso no desenvolvimento de dietas inertes para larvas de peixes marinhos é decorrente, principalmente, da focalização dos estudos somente na dieta em vez do entendimento das interações dieta $\times$ peixe .

Recentemente, Tesser \& Portella (2003) relataram que grânulos de dietamicroencapsuladacoletados notratodigestório de larvas de pacu co-alimentadas com náuplios de Artemia apresentavam maiores áreas de degradação que os retirados do trato de larvas alimentadas exclusivamente com a dieta seca, denotando influência dos náuplios de Artemia sobre a degradação da dieta inerte. No entanto,o efeitodessa possível contribuição enzimática não pôde ser avaliado.

Este trabalho foi desenvolvido com o objetivo de investigar a influência da suplementação com enzimas digestivas exógenas (pancreatina suína) à dieta microparticulada sobre a transição do alimento vivo para o inerte, o crescimento, a sobrevivência e as alterações morfológicas do trato digestório de larvas de pacu(Piaractus mesopotamicus).

\section{Material e Métodos}

Foram utilizadas 12.000 larvas de pacu ao final do período lecitotrófico, provenientes de desova induzida. As larvas foram contadas individualmente e estocadas em tanques plásticos de $100 \mathrm{~L}$ na densidade de 5 larvas/L, totalizando 500 larvas por tanque. Os tanques possuíam aeração e circulação de água contínua. $\mathrm{O}$ fotoperíodo foi o natural e a temperatura foi mantida em $31^{\circ} \mathrm{C}$ por meio de aquecedoressubmersos.

Utilizou-se uma ração microparticulada contendo $37 \%$ de proteína e $8 \%$ de lipídios, suplementada ou não com pancreatina suína na proporção de $0,25 \%$ do peso seco da dieta (Tabela 1). Esta suplementação forneceu atividade tríptica de $96.465 \mathrm{nmol} / \mathrm{min} / \mathrm{g}$ de ração. Como alimento vivo, foram utilizados náuplios de Artemia recém-eclodidos.

Foram testados os seguintes programas alimentares:

$\mathrm{JJ}$ : as larvas foram mantidas em jejum por todo o período experimental;

AV: as larvas receberam quantidades crescentes de náuplios de Artemia por todo o período experimental;

DM: as larvas foram alimentadas somente com dieta microparticulada;

DMP: as larvas foram alimentadas somente com dieta microparticulada suplementada com pancreatina suína;

AV5DM: as larvas foram alimentadas por cinco dias com náuplios de Artemia e, em seguida, foram submetidas à transição brusca para a dieta microparticulada; 
Tabela 1 - Composição da dieta experimental para larvas de pacu

Table 1 - Composition of the experimental diet for pacu larvae

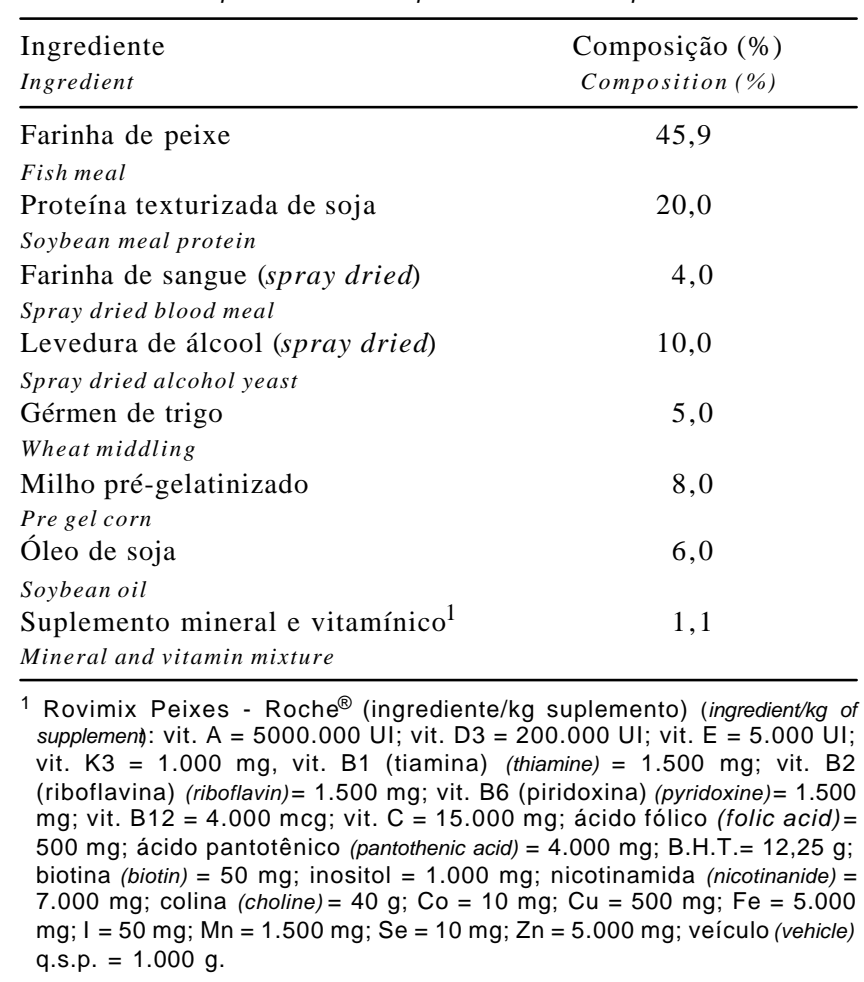

AV5DMP: as larvas foram alimentadas por cinco dias com náuplios de Artemia e, em seguida, foram submetidas à transição brusca para a dieta microparticulada com suplementação enzimática;

AV10DM: as larvas foram alimentadas por dez dias com náuplios deArtemiae, em seguida, passaram pela transição brusca para a dieta microparticulada;

AV10DMP: as larvas foram alimentadas por dez dias com náuplios de Artemia e, em seguida, foram submetidas à transição brusca para a dieta microparticulada com suplementação enzimática.

As larvas receberam inicialmente 350 náuplios de Artemia/larva (quantidade de alimento corrigida a cada três dias) e $4 \mathrm{~g}$ de ração. Essas porções foram fracionadas em oito refeições diárias, sendo consideradas em excesso. No primeiro dia experimental, quando estavam com cinco dias de vida, 30 larvas foram pesadas e medidas individualmente. Esse procedimento foi repetido a cada cinco dias até o $20 \underline{\text { odia }}$ com dez larvas por tanque. A última biometria foi realizada aos 28 dias de experimento, quando também se efetuou a contagem total das larvas remanescentes para determinação da sobrevivência final. Com os dados de peso e sobrevivência, foram calculadas a taxa de crescimento específico e a biomassa final utilizando-se as seguintes fórmulas:

$\mathrm{TCE}=100 \mathrm{x}((\operatorname{Ln}$ peso final $-L n$ peso inicial $) /$ período em dias);
Biomassa $=$ número final de sobreviventes $\times$ peso médio final.

As dietas com ou sem suplementação foram analisadas quanto aos teores de MS, PB e lipídios, conforme metodologia descrita pela AOAC (1965). Nas análises, não foi detectada nenhuma diferença entre as duas dietas.

A atividade de tripsina presente na dieta foi determinada segundo Kakade et al. (1974) utilizando-se N-alfa-benzoilDL-arginina-para-nitroanilida (BAPNA) como substrato.

Foram realizadas coletas para avaliação do desenvolvimento morfológico ao 5으, 10ํ, $15 \circ$, $20^{\circ}$ e $28^{\circ}$ dias de experimento. As larvas foram coletadas antes da primeira alimentação, fixadas em formol tamponado a $10 \%$ por 24 horas e transferidas para álcool 70\% até o processamento. Quatro larvas de cada tratamento foram inclusas em parafina, efetuando-se cortes de $5 \mu \mathrm{m}$ de espessura utilizando-se micrótomo rotatório. Os cortes semi-seriados foram corados com hematoxilina e eosina (HE) e submetidos à reação do ácido periódico de Schiff (PAS).

Adotou-se um delineamento inteiramente casualizado, com oito tratamentos e três repetições, em que os dados foram analisados quanto à normalidade (Shapiro - Wilk) e à homogeneidade da variância (Levene) antes da ANOVA. Quando houve diferença estatística, as médias foram contrastadas pelo teste Duncan a $5 \%$ de probabilidade. Valores expressos em porcentagem foram previamente transformados (arcoseno da raiz quadrada do valor precentual). Todas as análises foram realizadas com o programa Statistica 5.0.

\section{Resultados e Discussão}

A suplementação de enzimas exógenas promoveu efeito positivo na substituição do alimento vivo para o inerte em larvas de pacu. Os resultados de peso úmido (mg) ao longo do experimento são apresentados na Tabela 2. Aos cinco dias de experimento, ou quando as larvas estavam com dez dias de vida, houve diferença significativa entre o peso das larvas alimentadas com náuplios de Artemia e o daquelas alimentadas somente com alimento inerte.

Os pesos das larvas que receberam somente a dieta inerte suplementada ou não com pancreatina (DM e DMP) em nenhum momento diferiram entre e $\operatorname{si}(\mathrm{P}>0,05)$ ou daquelas que permaneceram em jejum (JJ). As larvas desses três tratamentos apresentaram mortalidade total no mesmo dia (11 $\mathrm{o}$ dia de experimento). Comportamento similar foi observado por Tesser et al. (2005) em larvas de pacu alimentadas desde o início da fase exógena com uma dieta microencapsulada comercial. Provavelmente as dietas testadas em ambos os experimentos não foram suficientemente 
atrativas ou nutricionalmente adequadas para a primeira alimentação de larvas de pacu.

Na segunda avaliação biométrica (10o dia de experimento), novamente as larvas dos tratamentos nos quais foram fornecidos náuplios de Artemia (AV, AV10DM e AV10DMP) apresentaram peso superior ao obtido nos demais tratamentos $(\mathrm{P}<0,05)$. As larvas que passaram pela substituição abrupta do alimento vivo para o inerte aos cinco dias de experimento (AV5DM e AV5DMP) não diferiram estatisticamente entre si, sendo observada leve redução de peso após estes cinco dias de alimentação exclusiva com a dieta inerte, independentemente de receberem suplementação enzimática, o que provavelmente está relacionado à baixa ingestão da dieta inerte. Jomori et al. (2003) também detectaram redução no crescimento de larvas de pacu após a substituição do alimento vivo pelo inerte, independentemente da idade. Tesser et al. (2005) verificaram que apenas $6,6 \%$ das larvas de pacu com 13 dias de vida ingeriram dieta microencapsulada comercial.

Na terceira avaliação biométrica realizada após o início do experimento (15 dias), notou-se o efeito positivo da suplementação enzimática entre as larvas dos tratamentos com substituição alimentar mais precoce (AV5DM e AV5DMP); aquelas que receberam a dieta suplementada com pancreatina apresentaram peso duas vezes superior $(\mathrm{P}<0,05)$ ao daquelas do tratamento AV5DM. Na 3a avaliação biométrica, ainda não foi observado efeito da suplementação enzimática sobre o peso $(\mathrm{P}>0,05)$ das larvas dos tratamentos AV10DM e AV10DMP, que já haviam passado pela transição alimentar há cinco dias. Todavia, verificou-se incremento do peso entre uma e outra avaliação biométrica, diferentemente do observado para as larvas dos tratamentos AV5DM e AV5DMP, após a transição brusca do alimento vivo para o inerte. $\mathrm{Na}$ 4 $\underline{\mathrm{a}}$ e na $5 \underline{\mathrm{a}}$ avaliações biométricas do peso, o efeito da suplementação foi evidenciado e as larvas que estavam recebendo a dieta inerte suplementada com enzimas exógenas apresentaram valores de peso superiores ao daquelas que se alimentaram da ração sem enzimas exógenas $(\mathrm{P}<0,05)$ (Tabela 2$)$. A mesma tendência foi observada para o crescimento em comprimento. Na Figura 1, nota-se que as larvas que passaram pela transição aos cinco dias de experimento, independentemente do tratamento, apresentaram ligeira redução no crescimento, que foi retomado logo em seguida. Nas larvas submetidas à transição alimentar aos dez dias de experimento, não foi constatada essa redução, sendo observado crescimento sempre positivo. Na última biometria, as larvas dos programas alimentares AV e AV10DMP não diferiram ( $\mathrm{P}>0,05)$ quanto ao comprimento, ao passo que as demais apresentaram valores médios significativamente diferentes $(\mathrm{P}<0,05)$.

Esse efeito positivo da suplementação enzimática so bre o crescimento das larvas de pacu está de acordo com os resultados obtidos por Kolkovski et al. (1993), que testaram a suplementação de pancreatina em uma microdieta para larvas de Sparus aurata obtiveram aumento de $30 \%$ na assimilação e de $200 \%$ no crescimento. Ao final do experimento, as larvas de pacu que receberam suplementação apresentaram peso médio 151 e $44 \%$ superior ao daquelas alimentadas com dietas sem enzimas (AV5DM e AV10DM, respectivamente).

Houve efeito positivo $(\mathrm{P}<0,05)$ da suplementação enzimática sobre a sobrevivência, principalmente nas larvas submetidas à transição alimentar aos cinco dias de experi-

Tabela 2 - Valores médios do peso $(\mathrm{mg}) \pm$ desvio-padrão $(\mathrm{n}=3)$ das larvas nos diferentes tratamentos ao longo do experimento Table 2 - Mean weight values $(\mathrm{mg}) \pm$ standard deviation $(n=3)$ of larvae submitted to different feeding programs

\begin{tabular}{|c|c|c|c|c|c|c|}
\hline \multirow[b]{2}{*}{$\begin{array}{l}\text { Programa alimentar } \\
\text { Feeding program }\end{array}$} & \multicolumn{6}{|c|}{$\begin{array}{c}\text { Dias de experimento } \\
\text { Days of experiment }\end{array}$} \\
\hline & $0^{*}$ & 5 & 10 & 15 & 20 & 28 \\
\hline $\mathrm{AV}$ & $0,509 \pm 0,12$ & $2,78^{\mathrm{a}} \pm 0,57$ & $7,42^{\mathrm{a}} \pm 1,05$ & $13,76^{\mathrm{a}} \pm 1,54$ & $30,93^{\mathrm{a}} \pm 0,58$ & $94,65^{\mathrm{a}} \pm 4,54$ \\
\hline AV10DM & $0,509 \pm 0,12$ & $2,40^{\mathrm{a}} \pm 0,24$ & $7,16^{\mathrm{a}} \pm 0,66$ & $9,47^{b} \pm 1,58$ & $19,28^{\mathrm{c}} \pm 1,36$ & $58,52^{c} \pm 6,43$ \\
\hline AV10DMP & $0,509 \pm 0,12$ & $2,70^{\mathrm{a}} \pm 0,36$ & $7,57^{\mathrm{a}} \pm 0,77$ & $9,63^{b} \pm 2,38$ & $22,02^{b} \pm 2,67$ & $84,67^{\mathrm{b}} \pm 3,56$ \\
\hline AV5DM & $0,509 \pm 0,12$ & $2,69^{a} \pm 0,22$ & $1,99^{b} \pm 0,30$ & $3,17^{\mathrm{d}} \pm 0,83$ & $3,70^{\mathrm{e}} \pm 0,04$ & $14,30^{\mathrm{e}} \pm 3,99$ \\
\hline AV5DMP & $0,509 \pm 0,12$ & $2,69^{\mathrm{a}} \pm 0,34$ & $2,44^{\mathrm{b}} \pm 0,23$ & $6,21^{c} \pm 0,65$ & $11,37^{\mathrm{d}} \pm 1,77$ & $35,99^{\mathrm{d}} \pm 1,52$ \\
\hline $\mathrm{DM}$ & $0,509 \pm 0,12$ & $0,51^{\mathrm{b}} \pm 0,05$ & $0,43^{\mathrm{c}} \pm 0,08$ & $\dagger$ & + & $\dagger$ \\
\hline DMP & $0,509 \pm 0,12$ & $0,54^{\mathrm{b}} \pm 0,02$ & $0,47^{\mathrm{c}} \pm 0,09$ & $\dagger$ & $\dagger$ & $\dagger$ \\
\hline $\mathrm{JJ}$ & $0,509 \pm 0,12$ & $0,45^{\mathrm{b}} \pm 0,01$ & $0,35^{\mathrm{c}} \pm 0,07$ & $\dagger$ & $\dagger$ & $\dagger$ \\
\hline
\end{tabular}

Médias com letras diferentes na mesma coluna diferem $(\mathrm{P}<0,05)$ pelo teste Duncan

Different letters in the same column denote statistical difference $(P<0.05)$ according to Duncan test.

†mortalidade total larval ao 11 으 dia de experimento.

biometria inicial.

t total mortality at $11^{\text {th }}$ day of the experiment

initial sample measurement. 


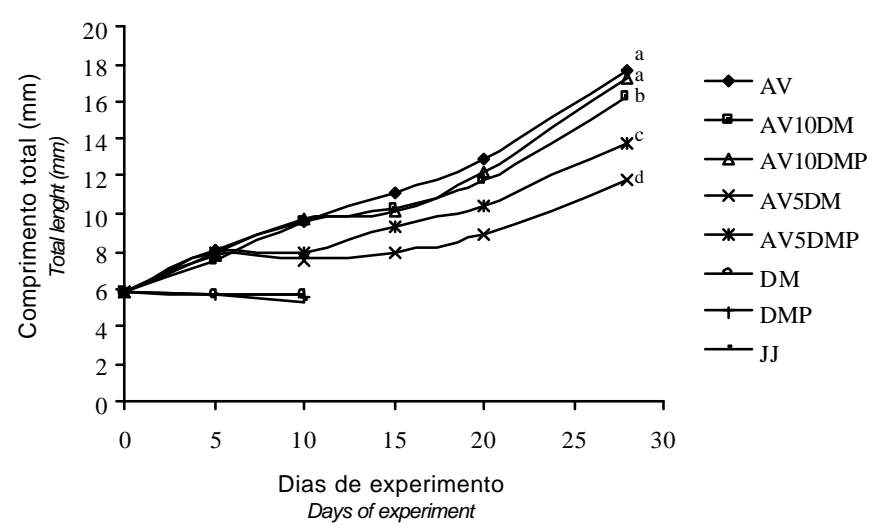

Figura 1 - Comprimento total $(\mathrm{mm})$ das larvas de pacu nos diferentes programas alimentares durante o experimento. Letras diferentes na última avaliação (28 dias de experimento) indicam diferença significativa $(\mathrm{P}<0,05)$ pelo teste Duncan.

Figure 1 - Total length $(\mathrm{mm})$ of pacu larvae submitted to different feeding treatments during the experiment. Different letters at the last evaluation (28 days of experiment) show statistical difference $(P<0.05)$ according to Duncan test.

mento (AV5DM e AV5DMP) (Tabela 3). Este resultado difere do relatado por Kolkovski et al. (1993), que observaram que a suplementação de dois níveis de pancreatina na dieta não resultou em diferença na sobrevivência de larvas de Sparus aurata.Além disso, a taxa de sobrevivência final das larvas de pacu do tratamento AV5DMP foi semelhante à daquelas que passaram pela substituição alimentar mais tardiamente (AV10DM).

As larvas que receberam a dieta suplementada com pancreatina apresentaram valores médios finais de biomassa superiores aos daquelas que não receberam suplementação $(\mathrm{P}<0,05)$. A mesma tendência foi observada para a taxa de crescimento específico, no entanto, a TCE obtida com larvasdo tratamento AV10DMP foi semelhante à observada no tratamento $\mathrm{AV}(\mathrm{P}>0,05)$, comprovando $\mathrm{a}$ eficiência da suplementação enzimática e do programa alimentar utilizado.

As alterações morfológicas do intestino e do fígado têm sido utilizadas como indicadores do estado nutricional de larvas de peixes alimentadas com diferentes dietas (Verreth et al., 1987; Dabrowski et al., 1989). Segner et al. (1994) relataram que as reservas energéticas hepáticas respondem sensivelmente às mudanças nutricionais ou às dietas nutricionalmente deficientes.

As larvas dos tratamentos JJ, DM e DMP apresentaram alterações morfológicas semelhantes tanto na primeira quanto na segunda observação ( $5 \underline{\mathrm{o}}$ e $10 \underline{\mathrm{o}}$ dia de experimento). Redução do volume citoplasmático dos hepatócitos decorrente da perda das reservas, núcleos escuros e perda do contorno celular foram as principais alterações ocorridas nesse órgão. O pâncreas sofreu desorganização acinar, escurecimento nuclear, além de ausência de grânulos de zimogênio, característica que, nas larvas em jejum, pode estar relacionada à perda da capacidade de sua síntese, conforme descrito por Strüssmann \& Takashima (1989).

As alterações observadas no intestino das larvas desses tratamentos (JJ, DM e DMP) foram o epitélio achatado e sem vilosidades, bem como a ausência de inclusões supranucleares e de células mucosas. $\mathrm{O}$ achatamento progressivo das vilosidades intestinais em larvas de Paralichthys californicus foi considerado por Gisbert et al. (2004) característico de larvas em jejum progressivo. Por outro lado, as larvas do tratamento AV apresentaram sempre o núcleo dos hepatócitos excêntrico, como conseqüência da grande quantidade de reservas (Figura 2A) e, principalmente, da presença de glicogênio, evidenciada pela forte reação positiva ao PAS. Vários grânulos de zimogênio foram encontrados no pâncreas exócrino, evidenciados pela reação ao PAS e visíveis também como grânulos eosinófilos na coloração de H/E. No intestino anterior e, principalmente, no posterior, verificavam-se várias inclusões supranucleares, as maiores com reação

Tabela 3 - Valores médios de sobrevivência final (\%), biomassa final e taxa de crescimento específico (\% por dia) ( \pm desvio-padrão) de larvas de pacu submetidas a diferentes programas alimentares

Table 3 - Mean values of final survival (\%), biomass and specific growth rate (\% per day) ( \pm standard deviation) in pacu larvae submitted to different feeding programs

\begin{tabular}{lccc}
\hline & $\begin{array}{c}\text { Sobrevivência }(\%) \\
\text { Survival }(\%)\end{array}$ & $\begin{array}{c}\text { Biomassa }(\mathrm{g}) \\
\text { Biomass }(g)\end{array}$ & $\begin{array}{c}\text { TCE }(\% / \mathrm{dia})^{1} \\
\text { SGR }(\% / \text { day })^{1}\end{array}$ \\
\hline AV & $79,83^{\mathrm{a}} \pm 8,26$ & $37,65^{\mathrm{a}} \pm 2,20$ & $18,66^{\mathrm{a}} \pm 0,17$ \\
AV10DM & $62,20^{\mathrm{bc}} \pm 7,37$ & $18,16^{\mathrm{c}} \pm 2,73$ & $16,93^{\mathrm{b}} \pm 0,40$ \\
AV10DMP & $73,62^{\mathrm{ab}} \pm 1,49$ & $31,14^{\mathrm{b}} \pm 0,67$ & $18,26^{\mathrm{a}} \pm 0,15$ \\
AV5DM & $36,02^{\mathrm{d}} \pm 6,62$ & $2,79^{\mathrm{e}} \pm 1,35$ & $11,84^{\mathrm{d}_{ \pm}}+1,01$ \\
AV5DMP & $51,76^{\mathrm{c}} \pm 10,05$ & $9,36^{\mathrm{d}} \pm 2,16$ & $15,21^{\mathrm{c}^{\mathrm{c}} \pm 0,15}$ \\
\hline
\end{tabular}

\footnotetext{
1 Taxa de crescimento específico. Valores calculados para todo o experimento.

Letras diferentes na mesma coluna indicam diferença estatística $(P<0,05)$ pelo teste Duncan.

${ }^{1}$ Specific growth rate. Values calculated for the whole experiment.

Different letters in the same column denote statistical difference $(P<0.05)$ according to Duncan test.
} 

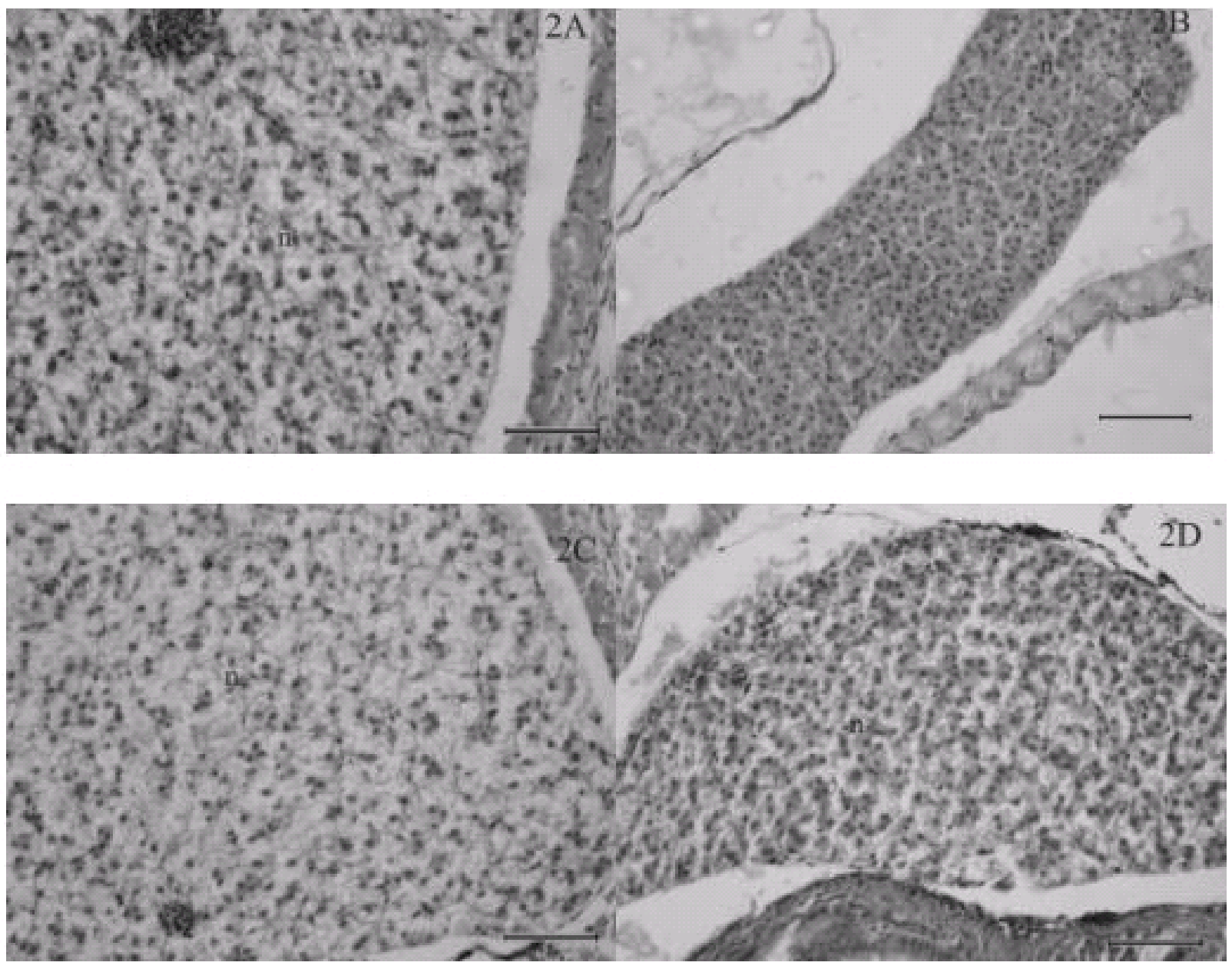

Figura 2 - Fígado de uma larva de pacu dos seguintes tratamentos: AV aos 20 dias (A), AV5DM aos 15 dias (B), AV10DMP aos 28 dias (C) e AV5DMP aos 10 dias de experimento (D) (400X - HE).

Figure 2 - Pacu liver fed the following treatments: AV at $20^{\text {th }}$ day $(A), A V 5 D M$ at $15^{\text {th }}$ day (B), AV10DMP at 28 th day (C) and AV5DMP at $10^{\text {th }}$ day (D) of experiment $(400 X-H E)$.

Barras representam $50 \mu \mathrm{m} ; \mathrm{n}=$ núcleo.

Bars represent $50 \mu \mathrm{m} ; n=$ nucleous.

negativa ao PAS; no entanto, no intestino anterior, havia pequenas inclusões PAS positivas.

Quanto às larvas que passaram pela transição alimentar precoce e receberam dietas contendo (AV5DMP) ou não (AV5DM) pancreatina, verificaram-se diferenças nos órgãos estudados (fígado, intestino e pâncreas) em todas as coletas realizadas. As larvas que receberam a suplementação enzimática apresentaram maior quantidade de vacúolos de reservas no citoplasma dos hepatócitos; no entanto, os núcleos não foram deslocados para a periferia (Figuras 2B e 2D). No intestino, principalmente no posterior, foi observada maior quantidade de vacúolos supranucleares, com inclusões PAS negativas. No pâncreas, verificou-se maior quantidade de grânulos de zimogênio nas larvas alimentadas com a dieta suplementada. A presença de maior quantidade de reserva no fígado e vacuolização do intestino, mesmo após a transição alimentar aos cinco dias, sugere que, mesmo com uma ligeira redução no peso, as larvas do tratamento AV5DMP podem ter recebido maior aporte de nutrientes, como resultado dos efeitos da suplementação enzimática. A presença de vacúolos nos enterócitos e nos hepatócitos caracteriza a ocorrência de absorção de nutrientes (Yúfera et al., 1996), que refletiu nos resultados de crescimento, visto que as larvas do tratamento AV5DMP apresentaram peso maior (Tabela 2) que o das alimentadas com a dieta sem enzimas exógenas.

Por outro lado, não foram constatadas diferenças morfológicas entre as larvas que, aos dez dias de experimento, passaram pela transição abrupta recebendo dietas com suplementação e aquelas que não receberam suplementação enzimática. Aumento na quantidade de vacúolos de reservas no fígado e aumento na quantidade de inclusões 
supranucleares no intestino foram evidenciados com o aumento da idade das larvas. Na última observação (28 dias de experimento), não foi encontrada nenhuma diferença morfológica evidente entre as larvas dos tratamentos AV, AV10DM e AV10DMP (Figura 2C).

Resultados contraditórios foram publicados sobre a importância da suplementação enzimática na alimentação de larvas de peixes (Kolkovski, 2001). Segundo Cahu \& Zambonino Infante (2001), o trato digestório de larvas de peixes possui enzimas digestivas desde a primeira alimentação e o aparecimento dessas atividades enzimáticas está relacionado às transformações morfológicas, seguindo uma seqüência cronológica. No entanto, é possível que as larvas de peixes não possuam enzimas em quantidades suficientes para digerir dietas inertes (Kolkovski, 2001). Vários autores enfatizaram a importância da diferenciação do estômago e da digestão ácida no sucesso da utilização de dietas inertes e, em última análise, na substituição do alimento vivo pelo artificial (Galvão et al., 1997; Martinez et al., 1999; Vega-Orellana et al., 2006).

Cahu \& Zambonino Infante (2001) afirmam que a falta de estômago funcional não impede a digestão protéica em larvas de peixes, visto que a digestão é realizada pelas enzimas proteolíticas pancreáticas. No entanto, Rønnestad et al. (1999) sugeriram que, na ausência de $\mathrm{HCl}$ e da secreção de pepsina, a proteína poderia não sofrer desnaturação, dificultando a ação das enzimas proteolíticas alcalinas. Pouco se conhece sobre a seqüência de aparecimento das enzimas digestivas em larvas de pacu. Tesser (2002) verificou que larvas de pacu com 7,0 mm de comprimento total (16 dias de vida) já apresentavam estômago diferenciado, com glândulas gástricas. Mesmo que as larvas dos tratamentos em que a substituição foi realizada aos 10 dias de alimentação exógena (15 dias de vida e aproximadamente $9,5 \mathrm{~mm}$ de comprimento total) já tivessem estômago diferenciado, a suplementação enzimática proporcionou efeito positivo sobre o crescimento e a sobrevivência. Em dois trabalhos com juvenis de tambaqui (Colossoma macropomum) alimentados com dietas suplementadas com amilase (Nunes et al., 2004a) ou lipase (Nunes et al., 2004b), foram relatados melhores resultados de ganho de peso entre os juvenis que receberam suplementação enzimática. Entretanto, neste estudo, não foi possível concluir exatamente qual enzima teve maior influência sobre o crescimento e a sobrevivência de larvas de pacu.

Kolkovski et al. (1997) e Kolkovski et al. (2000), em estudo com larvas de Dicentrarchus labrax e Perca flavensis, respectivamente, não encontraram efeito significativo da suplementação de enzimas exógenas sobre o crescimento e a sobrevivência dos animais, sugerindo que a quantidade de enzimas ativas provenientes da dieta não foi suficiente para promover efeito sobre o desempenho produtivo. Outra possibilidade avaliada pelos autores seria a de que essas espécies não respondem à suplementação de enzimas exógenas. Por outro lado, a adição de enzimas em dietas pode acarretar pré-hidrólise dos seus componentes antes mesmo do oferecimento aos peixes (Dabrowska et al., 1979). Esse fato foi confirmado recentemente por Stone et al. (2003), que notaram aumento na quantidade de açúcares na dieta suplementada em comparação àquela sem suplementação.

Considerando os resultados de crescimento e desenvolvimento do sistema digestório, o efeito da adição da pancreatina na dieta artificial foi mais pronunciado quando as larvas receberam a suplementação em uma fase mais precoce de desenvolvimento, aos cinco dias de alimentação exógena.

Esses resultados demonstram que, a partir de 7,0 mg de peso úmido, larvas de pacu podem ser submetidas à transição alimentar, pois não há comprometimento da sobrevivência final quando alimentadas com dieta suplementada com enzimas exógenas. No entanto, ajustes nutricionais da dieta e o uso de atrativos devem ser realizados para que o crescimento seja comparável ao de larvas alimentadas com náuplios de Artemia.

\section{Conclusões}

A adição de enzimas exógenas em dietas para larvas de pacu determinou melhora no crescimento e na sobrevivência larval e alterou morfologicamente (sem prejuízos patológicos) os órgãos estudados, podendo ser recomendada em dietas para larvas desta espécie.

\section{Agradecimento}

À Coordenação de Pessoal de Nível Superior (CAPES) pela concessão de bolsa de Doutorado ao primeiro autor. Ao Conselho Nacional de Desenvolvimento Científico e Tecnológico $(\mathrm{CNPq})$ pelo Auxílio Financeiro à Pesquisa (Processo 477812/03-1).

\section{Literatura Citada}

ALARCÓN, F.J.; MOYANO, F.; DÍAZ, M. Effect of inhibitors present in protein sources on digestive proteases of juvenile sea bream (Sparus aurata). Aquatic Living Resources, v.12, n.4, p.223-238, 1999.

ASSOCIATION OF OFFICIAL AGRICULTURE CHEMISTS AOAC. Official methods of analysis of the Association of Agriculture Chemists. Washington, D.C.: 1965. 937p.

BENGSTON, D.A. A comprehensive program for the evaluation of artificial diets. Journal of the World Aquaculture Society v. 24, n.2, p.285-293, 1993.

BOULHIC, M.; GABAUDAN, J. Histological study of the organogenesis of the digestive system and swim bladder of the 
Dover sole, Solea solea (Linneaus, 1758). Aquaculture, v.102, p.373-396, 1992.

CAHU, C.L.; ZAMBONINO INFANTE, J.L. Substitution of live food by formulated diets in marine fish larvae. Aquaculture, v.200, p.161-80, 2001.

CONCEIÇÃO, L.E.C.; DERSJANT-LI, Y.; VERRETH, J.A.J. Cost of growth in larval and juvenile African catfish (Clarias gariepinus) in relation to growth rate, food intake and oxygen consumption. Aquaculture, v.161, p.95-106, 1998.

COUSIN, J.C.B.; BAUDAIN-LAURENCIN, F.; GABAUDAN, J. Ontogeny of enzymatic activities in fed and fasting turbot, Scophtalmus maximus L. Journal of Fish Biology, v.30, p.15-33, 1987.

DABROWSKA, H.; GRUDNIEWSKI, C.; DABROWSKI, K. Artificial diet for common carp: effect of the addition of enzymes extracts. The Progressive Fish-Culturist, v.41, p.196-200, 1979 .

DABROWSKI, K. The feeding of fish larvae: present "state of the art" and perspectives. Reproduction Nutrition and Development, v.24, p.807-833, 1984.

DABROWSKI, K.; SEGNER, H.; DALLINGER, R. et al. Rearing of roach larvae: the vitamin $\mathrm{C}$-minerals interrelationship and nutrition-related histology of the liver and intestine. Journal of Animal Phsyiology and Animal Nutrition, v.62, p.188202, 1989

GALVÃO, M.S.N.; FENERICH-VERANI, N.; YAMANAKA, N. et al. Histologia do sistema digestivo da tainha Mugil platanus Günther, 1880 (Osteichthyes, Mugilidae) durante as fases larval e juvenil. Boletim do Instituto de Pesca, v.24, p.91-100, 1997.

GISBERT, E.; CONKLIN, D.B; PIEDRAHITA, R.H. Effects of delayed first feeding on the nutritional condition and mortality of California halibut larvae. Journal of Fish Biology, v.64, p.116-132, 2004.

GOVONI, J.J.; BOEHLER, G.W.; WATANABE, Y. The physiology of digestion in fish larvae. Environmetal Biology of Fishes, v.16, p.59-77, 1986.

HOLT, G.J. Feeding larval red drum on microparticulate diets in a closed recirculating water system. Journal of the World Aquaculture Society, v.24, n.p.225-230, 1993.

JOMORI, R.K.; PORTELLA, M.C.; CARNEIRO, D.J. Artificial diet during pacu, Piaractus mesopotamicus larviculture. In: WORLD AQUACULTURE 2003, 2003, Salvador. Anais... Salvador: 2003. p.383.

KAKADE, M.L.; RACKIS, J.J.; MCGHEE, J.G. Determination of trypsin inhibitor activity of soy products. A collaborative analysis of an improved procedure. Cereal Chemistry, v.5, p.357-352, 1974

KOLKOVSKI, S.; TANDLER, A.; KISSIL, G.WN. et al. The effect of dietary exogenous enzymes on ingestion, assimilation, growth and survival of gilthead seabream (Sparus aurata, Sparidae, Linnaeus) larvae. Fish Physiology and Biochemistry, v.12, p.203-209, 1993

KOLKOWSKI, S.; TANDLER, A.; IZQUIERDO, M.S. Effects of live food and dietary digestive enzymes on the efficiency of microdiets for seabass (Dicentrarchus labrax) larvae. Aquaculture, v.148, p.313-322, 1997.

KOLKOVSKI, S.; YACKEY, C.; CZESNY, S. et al. The effect of microdiet supplementation of dietary enzymes and a hormone on growth and enzyme activity in yellow perch juveniles. North American Journal of Aquaculture, v.62, p.130-134, 2000.

KOLKOVSKI, S. Digestive enzymes in fish larvae and juveniles implications and applications to formulated diets. Aquaculture, v.200, p.181-201, 2001

KUROKAWA, T.; SHIRAISHI, M.; SUZUKI, T. Quantification of exogenous protease derived from zooplankton in the intestine of Japanese sardine (Sardinops melanotictus) larvae. Aquaculture, v.161, p.491-499, 1998.

LAUFF, M.; HOFFER, R. Proteolic enzymes in fish development and the importance of dietary enzymes. Aquaculture, v.37, p.335-346, 1984
MARTINEZ, I.; MOYANO, F.J.; FERNANDEZ-DIAZ, C. et al. Digestive enzyme activity during larval development of the Senegal sole (Solea senegalensis). Fish Physiology and Biochemistry, v.21, p.317-323, 1999.

NUNES, E.S.S.; CAVERO, B.A.; PEREIRA FILHO, M. et al. Desempenho zootécnico de juvenis de tambaqui alimentados com ração suplementada com amilase exógena. In: AQUIMERCO, 2004, Vitória. Anais... Vitória: 2004a. p.73.

NUNES, E.S.S.; CAVERO, B.A.; PEREIRA FILHO, M. et al. Desempenho zootécnico de juvenis de tambaqui alimentados com ração suplementada com lipase exógena. In: AQUIMERCO, 2004, Vitória. Anais... Vitória: 2004b. p.74.

ÖNAL, U.; LANGDON, C. Characterization of two microparticulate types for delivery of food to altricial fish larvae.Aquaculture Nutrition, v.6, p.159-170, 2000.

PLANAS, M.; CUNHA, I. Larviculture of marine fish: problems and perspectives. Aquaculture, v.77, p.171-190, 1999.

ROSENLUND, G.; STOSS, J.; TALBOT, C. Co-feeding marine fish larvae with inert and live diets. Aquaculture, v.155, p.183$191,1997$.

RØNNESTAD. I.; THORSEN, A.; FINN, R.N. Fish larval nutrition: a review of recent advances in the roles of amino acids. Aquaculture, v.177, p.201-216, 1999.

RÖSCH, R.; SEGNER, H. Development of dry food for larvae of Coregonus lavaretus L. I Growth, food digestion and fat absorption. Aquaculture, v.91, p.101-115, 1990.

SEGNER, H.; STORCH, V.; REINECKE, M. et al. The development of functional digestive and metabolic organs in turbot, Scophthalmus maximus. Marine Biology, v.119, p.471-486, 1994

STONE, D.A.J.; ALLAN, G.L.; ANDERSON, AJ. Carbohydrate utilization by juvenile silver perch, Bidyanus bidyanus (Mitchell). IV. Can dietary enzymes increase digestibility energy from wheat starch, wheat and dehulled lupin? Aquaculture Research, v.34, p.135-147, 2003.

STRÜSSMANN, C.A.; TAKASHIMA, F. PNR, histology and morphology of starved pejerrey Odontesthes bonariensis larvae. Nippon Suisan Gakkaishi, v.55, p.237-246, 1989.

TESSER, M.B. Desenvolvimento do trato digestório e crescimento de larvas de pacu, Piaractus mesopotamicus (Holmberg, 1887) em sistemas de co-alimentação com náuplios de Artemia e dieta microencapsulada . Jaboticabal: Universidade Estadual Paulista, 2002. 59p. Dissertação (Mestrado em Aqüicultura) - Universidade Estadual Paulista, 2002.

TESSER, M.B.; CARNEIRO, D.J.; PORTELLA, M.C. Co-feeding of pacu (Piaractus mesopotamicus, Holmberg, 1887) larvae with Artemia and microencapsulated diet. Journal of Applied Aquaculture, v.17, p.47-59, 2005.

TESSER, M.B.; PORTELLA, M.C. Degradation analysis of microencapsulated diet in pacu (Piaractus mesopotamicus Holmberg, 1887) larvae intestine through scanning electron microscopy. Acta Scientiarum, v.25, p.49-52, 2003.

VEGA-ORELLANA, O.; FRACALOSSI, D.M.; SUGAI, J.K. Dourado (Salminus brasiliensis) larviculture: weaning and ontogenetic development of digestive proteinases. Aquaculture, v.253, p.484-493, 2006.

VERRETH, J.; STORCH, V.; SEGNER, H. A comparative study on nutritional quality of decapsulated Artemia cysts, microencapsulated egg diet and enriched dry feeds for early weaning of Clarias gariepinus (Burchel) larvae. Aquaculture, v.63, p.269-282, 1987.

YÚFERA, M.; SARASQUETE, M.C.; FERNÁNDEZ-DÍAZ, C. Testing protein-walled microcapsules for the rearing of firstfeeding gilthead sea bream (Sparus aurata) larvae. Marine and Freshwater Research, v.47, p.211-216, 1996.

Recebido: 05/09/05 Aprovado: 07/08/06 